\title{
Evaluation of a Current Source Active Power Filter to Reduce the DC Bus Capacitor in a Hybrid Electric Vehicle Traction Drive
}

\author{
Shengnan Li \\ Student Member, IEEE \\ The University of Tennessee \\ Department of Electrical Engineering \\ and Computer Science \\ Knoxville, TN, 37996, USA \\ sli14@utk.edu
}

\author{
Burak Ozpineci \\ Senior Member, IEEE \\ Oak Ridge National Laboratory \\ Oak Ridge, TN, 37831-6472, USA \\ ozpinecib@ornl.gov
}

\author{
Leon M. Tolbert \\ Senior Member, IEEE \\ The University of Tennessee \\ Department of Electrical Engineering \\ and Computer Science \\ Knoxville, TN, 37996, USA \\ tolbert@utk.edu
}

\begin{abstract}
In hybrid electric vehicles (HEV), a batterypowered three-phase inverter is used to drive the traction motor. Due to the switching behavior of this inverter, significant harmonic currents are present on the dc side of the inverter. Traditionally, a bulky capacitor is used to filter these harmonics. In this paper, an active filtering method is evaluated to substitute for the de bus capacitor. The active power filter (APF), composed of power electronic switches and an inductor, works as a current-source inverter. The operation principle of the proposed method is described and implemented in Matlab/Simulink. The method has been proposed before but the practical feasibility of this method has not been evaluated. In this paper, several crucial design parameters in association with the filtering effect, such as voltage band and the values of the inductor and the smoothing capacitor are identified, and the dependence of system performance on these parameters is illustrated. Finally, the underlying problems for practical implementation are discussed.
\end{abstract}

Index Terms-Active power filter, Current-source inverter, dc bus capacitor, Electric vehicle, Harmonic current, Hybrid electric vehicle.

\section{INTRODUCTION}

There is a growing interest in Electric Vehicles (EV) due to energy crises and environmental concerns. However, the development of EVs has been stunted by limited battery technology. HEVs combine the conventional internal combustion engine, electric motor, and energy storage device (for example, batteries and ultracapacitors). They offer a good solution to reduce the emissions and to increase the gas mileage of conventional vehicles and to eliminate the problems of the limited range of EVs.

In an electric traction system composed of a battery, dc bus, three-phase inverter and an induction motor, harmonic current in the dc bus introduced by switching behavior of the inverter is significant. Excessive harmonic current can greatly disturb the dc bus voltage, cause thermal stress on the dc bus capacitor and interference with communication and control system, additional heat, audible noise, mechanical stress, and vibration [1]. DC bus harmonic current analysis and simulation have been discussed in detail in [1].
The dc bus capacitor is used to filter the dc bus current harmonics and to reduce the dc voltage ripple. It occupies 35$40 \%$ of the whole traction inverter volume and weight and costs $23 \%$ of the inverter. EV and HEV manufacturers are interested in savings in the cost, weight, and volume of these capacitors. An active power filter could be one way to reduce the capacitor size.

Another way of reducing the size of an EV/HEV traction inverter is reducing the size of the heat sink by running the inverter at a higher temperature $\left(>150^{\circ} \mathrm{C}\right)$, possibly using silicon carbide $(\mathrm{SiC})$ power devices. For the inverter to run at high temperatures, the dc bus capacitor should be capable of running at these temperatures. Typically, film capacitors, which are not available to run at $\mathrm{SiC}$ temperatures, are used as dc bus capacitors in EVs/HEVs. An alternative for high temperature operation is the ceramic capacitor, which is not preferred by car manufacturers because of its destructive failure mechanism. An active filter with semiconductor switches, a small capacitor, and an inductor could be a better solution at high temperatures to replace the dc bus capacitor.

In the literature, two methods have been studied to solve the dc bus harmonic current problem. One is to improve the modulation method of the inverter to mitigate harmonics [1][2][3], the other is to use advanced filtering methods [4][5][6], namely, film capacitor and an active power filter.

APF technology is now a mature technology in utility applications for providing compensation for harmonics, reactive power and/or neutral current [7][8][9]. It is also used to eliminate the pulsating dc side currents or voltages of rectifiers caused by AC line input voltage [10][11]. Some researchers have looked into applying active filters into the dc bus to eliminate high frequency harmonics by using current-source inverters [4].

Reference [4] applies an active filter to a $1.5 \mathrm{~kW}$ motor drive system. It proposes a control method that modulates the output current of the filter to follow the shape of the high frequency harmonic current in the dc bus generated by the inverter. Although the proposed APF methods can replace the bulky dc bus capacitor functionally, the authors did not evaluate the feasibility of its practical application, the volume 
increase by adding APF, the losses associated with it and also the cost. Moreover, the power level of a traction drive system in EVs or HEVs is much higher. There might be different problems at low power level and high power level. This paper addresses these issues by presenting a method to replace the bulky capacitor by an active filter in a $55 \mathrm{~kW}$ traction drive system and analyzing the problems and barriers in this method.

\section{OPERATION PRINCIPLE OF THE APF Method}

A typical traction drive system is shown in Fig. 1. It consists of a dc source, an APF, a three-phase inverter, and a traction motor, which in this case is an induction motor. The synthesis of a smooth sinusoidal current, with minimum harmonics, for the ac motor drive with a stiff dc voltage source requires a high rate of switching in different combinations of the inverter switches. The most common used modulation methods are sinusoidal pulse-width modulation (SPWM) and space vector modulation (SVM). By using these modulation methods, the output current of the inverter can be modulated in a desired sinusoidal shape, but the dc side ripple current drawn from the battery can be significant. To demonstrate the waveforms of dc bus current, a specific example considering a three-phase inverter feeding a squirrel cage induction motor is used. The system parameters are shown in Table I.

TABLE I

PARAMETERS OF THE TRACTION DRIVE SYSTEM

\begin{tabular}{|c|c|}
\hline Parameter & Value \\
\hline dc bus voltage $V_{\mathrm{dc}}$ & $500 \mathrm{~V}$ \\
\hline dc bus capacitor $C_{\mathrm{dc}}$ & $2200 \mu \mathrm{F}$ \\
\hline Three-phase inverter switching frequency $f_{\mathrm{sw}}$ & $10 \mathrm{kHz}$ \\
\hline Three-phase inverter modulation frequency $f_{\mathrm{m}}$ & $50 \mathrm{~Hz}$ \\
\hline Output power $P_{\text {out }}$ & $55 \mathrm{~kW}$ \\
\hline Number of poles in IM & 2 \\
\hline Stator resistance of IM & $0.19 \Omega$ \\
\hline Rotor resistance of IM & $0.39 \Omega$ \\
\hline Magnetizing inductance of IM & $4 \mathrm{mH}$ \\
\hline Stator and rotor leakage inductance & $270 \mu \mathrm{H}$ \\
\hline
\end{tabular}

The dc bus current can be obtained through Matlab/Simulink simulation using PLECS toolbox. Fig. 2 and 3 show the dc bus ripple current before filtering and the Fourier transform of this current, respectively. Without smoothing of the dc bus capacitor, the current pulsates between -70 A and $220 \mathrm{~A}$, which is the peak phase current for the motor in this simulation. From Fig. 3, we can see the dc component is $110 \mathrm{~A}$, there are high harmonic components at $f_{\mathrm{sw}} \pm 3 \times f_{\mathrm{m}}, \quad 2 \times f_{\mathrm{sw}}, 2 \times f_{\mathrm{sw}} \pm 6 \times f_{\mathrm{m}}, 3 \times f_{\mathrm{sw}} \pm 3 \times f_{\mathrm{m}}, 4 \times f_{\mathrm{sw}}, 4 \times f_{\mathrm{sw}} \pm 6 \times f_{\mathrm{m}}$, and some low harmonic components at higher frequency.

The purpose of APF is to absorb the ripple current and leave only the dc component. In order to fabricate the ripple current, an H-bridge current-source inverter topology is used as shown in Fig. 4. It is composed of an inductor and a single

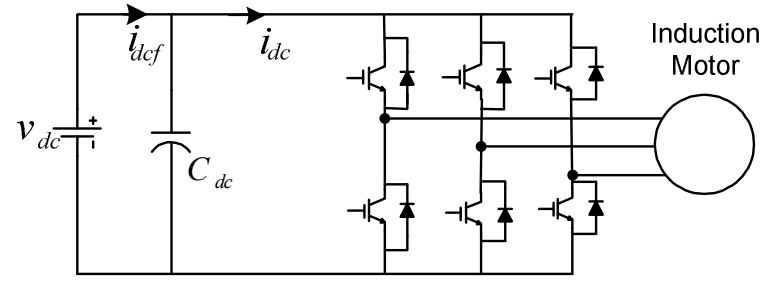

Fig. 1. HEV traction trive system.

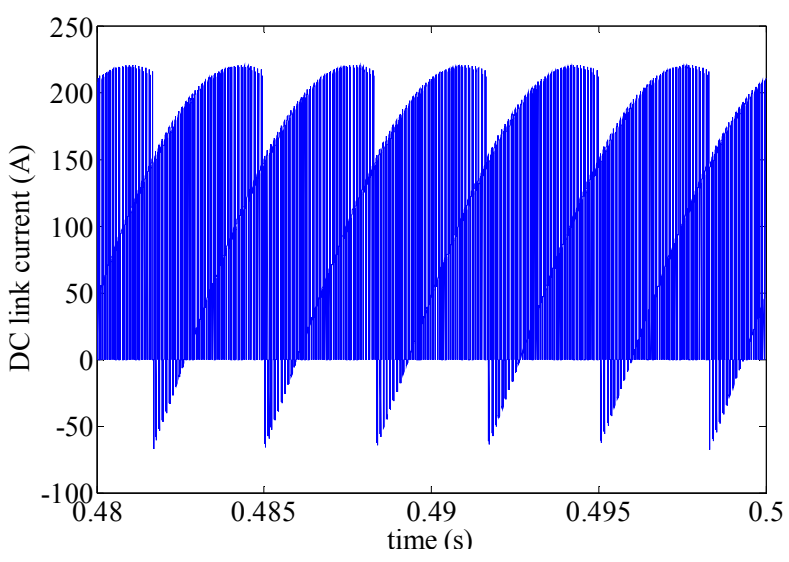

Fig. 2. Simulated dc bus current in HEV motor drive.

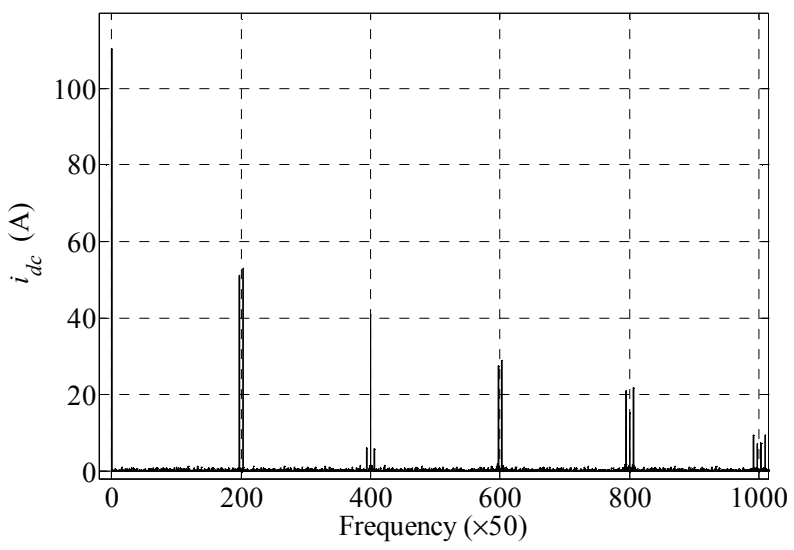

Fig. 3. Harmonic spectrum of dc bus current.

phase full bridge inverter. A small capacitor is still necessary for some smoothing, but it is much smaller than the original dc bus capacitor. Note that the figure shows reverse blocking IGBTs. Reverse blocking IGBT have limited commercial availability with the highest rated ones rated at $1200 \mathrm{~V}$ and $55 \mathrm{~A}$. In the simulation study for this project, conventional IGBTs are used with series diodes for reverse blocking.

In order to illustrate the operation principle, equivalent circuits of the traction drive system are derived as in [4] and are shown in Fig. 5. A ripple current source $i_{\text {ripple }}$ imitates the input harmonic current of the three-phase inverter. According to the direction of the filter current and harmonic current, the APF can operate in four modes. Fig. 6 illustrates the 
operating modes by indicating the current paths. The operating modes are explained in detail as follows.

Mode 1: when the ripple current $i_{\text {ripple }}$ flows into the load, which is defined as positive, filter switches $S_{1}$ and $S_{4}$ are closed (interval between time T1 and T2 in Fig. 6) and the inductor current $i_{L}$ is injected into the dc bus. The direction of filter current $i_{\text {filter }}$ in this mode is defined as negative. Since $i_{\text {filter }}$ is larger than $i_{\text {ripple }}, i_{\text {filter }}$ charges the capacitor and hence $v_{d c}$ increases. The dc bus voltage can be described by the following equation:

$$
C_{d c} \frac{d v_{d c}}{d t}=-i_{\text {ripple }}-i_{\text {filter }}
$$

Mode 2 starts once $v_{d c}$ reaches the upper boundary of its preset hysteresis band.

Mode 2: In order to reduce $v_{d c}, \mathrm{~S}_{1}$ and $\mathrm{S}_{2}$ are closed. $i_{L}$ freewheels through them. Since ripple current is still positive, it discharges the capacitor, and hence $v_{d c}$ decreases. It can be described by (2):

$$
C_{d c} \frac{d v_{d c}}{d t}=-i_{\text {ripple }}
$$

When $v_{d c}$ reaches the lower bound, this mode ends. It lasts from $\mathrm{T}_{2}$ to $\mathrm{T}_{3}$.

Mode 3: When the ripple current is negative, $\mathrm{S}_{2}$ and $\mathrm{S}_{3}$ are closed to produce positive $i_{\text {filter }}$. $i_{\text {ripple }}$ goes into the filter. Since $i_{\text {filter }}$ is larger than $i_{\text {ripple }}$, the total current discharges the capacitor. $v_{d c}$ decreases as shown in interval $\left[\mathrm{T}_{4}, \mathrm{~T}_{5}\right]$ in Fig. 6. Once it reaches the lower boundary, mode 3 ends. Equation (3) describes the voltage of the dc bus during this period:

$$
C_{d c} \frac{d v_{\text {bus }}}{d t}=-i_{\text {ripple }}-i_{\text {filter }}
$$

Mode 4: In this mode, $\mathrm{S}_{3}$ and $\mathrm{S}_{4}$ are closed. The inductor current freewheels through $\mathrm{S}_{3}$ and $\mathrm{S}_{4}$. $i_{\text {ripple }}$ charges the capacitor; thus, $v_{d c}$ increases. This mode corresponds to the time interval $\left[\mathrm{T}_{5}, \mathrm{~T}_{6}\right]$ and can be described by (4):

$$
C_{d c} \frac{d v_{\text {bus }}}{d t}=-i_{\text {ripple }}
$$

According to the operation principle depicted above, the switching strategy of an active filter is influenced by two variables: dc bus voltage ripple and ripple current generated by the three-phase inverter. The control circuit of the active filter is shown in Fig. 7. Two control loops are used to generate the control signals. DC bus voltage $v_{\mathrm{dc}}$ is detected and filtered to get an average value $V_{d c}$. Voltage ripple $\Delta v_{d c}$ is obtained by subtracting average value $V_{d c}$ from $v_{d c}$, and then it is fed to a hysteresis-band controller to generate a logic signal $\mathrm{C}_{1}$. In order to compensate the loss in the inductor and keep the inductor current to the desired value $I_{L}, i_{L}$ is controlled by a feedback PI controller, the error $e_{i L}$ is taken

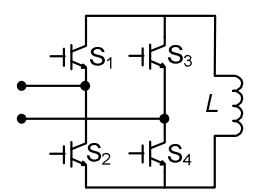

Fig. 4. Active power filter.

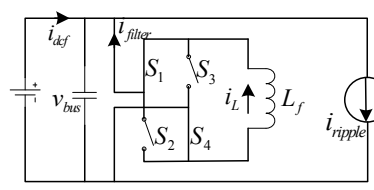

(a) Mode 1

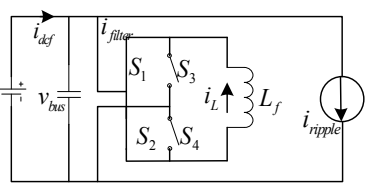

(b) Mode 2

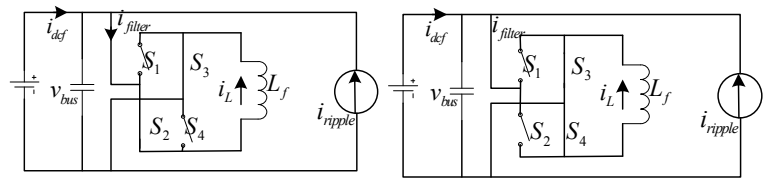

(c) Mode 3

(d) Mode 4

Fig. 5. Equivalent circuits under different operating modes.

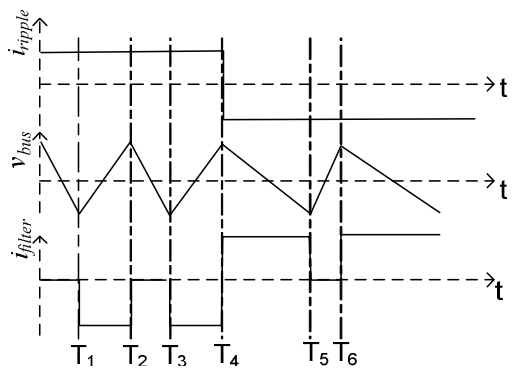

Fig. 6. Operating current and voltage waveforms of APF.

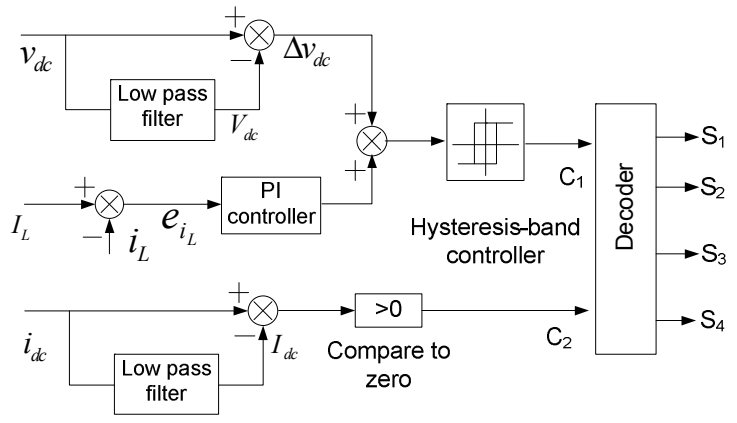

Fig. 7. Control circuit of active power filter.

through a PI controller and the output is added to $\Delta v_{d c}$. In addition, the polarity of the current ripple is detected as signal $\mathrm{C}_{2}$. A decoder is used to generate the switching signal for $\mathrm{S}_{1}$, $\mathrm{S}_{2}, \mathrm{~S}_{3}$, and $\mathrm{S}_{4}$.

\section{Simulation Results}

In order to verify the feasibility of the APF method, a computer simulation is undertaken. The motor drive system with APF was modeled and simulated using Matlab/Simulink with the PLECS toolbox, according to the topology and 
operation principle described above. The system parameters are the same as listed in the last section, except that in the APF method a $100 \mu \mathrm{F}$ smoothing capacitor is used instead of the $2200 \mu \mathrm{F}$ capacitor. Moreover, 4 IGBTs, 2 diodes and a 5 $\mathrm{mH}$ inductor are used for the active filter. For comparison purposes, the case with the large capacitor only filter has also been studied.

Fig. 8 shows the simulation results. The left column is current and voltage waveforms in the original single capacitor case with no APF, and the right one is for the APF case. Fig. 8(a) shows the dc bus current before and after filtering. Fig. 8(b) shows the zoomed plot of the dc input current. The current ripple is between $160 \mathrm{~A}$ and $220 \mathrm{~A}$ before filtering. The fundamental frequency of dc bus current ripple is at 3 $\mathrm{kHz}$, which is six times the modulation frequency, because of the modulation of the three-phase inverter. In the passive method, the current ripple fluctuates from 3 A peak-to-peak, to $10 \mathrm{~A} \mathrm{p}$-p. While in APF method, the ripple current is identically $10 \mathrm{~A} \mathrm{p}-\mathrm{p}$, since the control method is hysteresis control to keep the current within a bandwidth. Fig. 8 (c) shows the voltage ripple of $\mathrm{dc}$ bus. The same as current, in the passive method, the voltage ripple changes from $0.5 \mathrm{~V} \mathrm{p}$ $\mathrm{p}$ to $2 \mathrm{~V} \mathrm{p}-\mathrm{p}$, while in the APF method it is strictly at $2 \mathrm{~V} \mathrm{p}-\mathrm{p}$.

It can be seen that functionally the active filter is the same as the passive capacitor.

Fig. 9 shows the frequency spectrum of the dc input
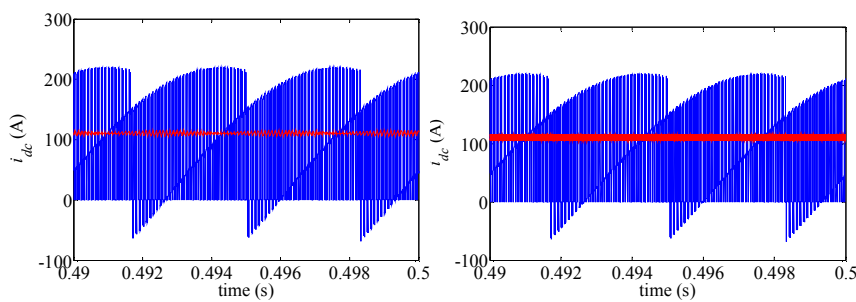

(a) Inverter input current (blue) and dc input current (red)
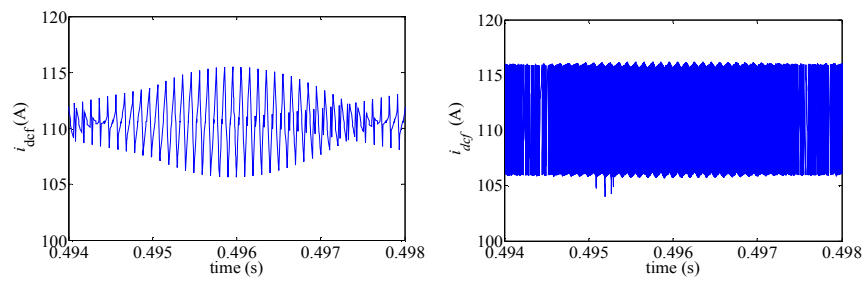

(b) dc input current
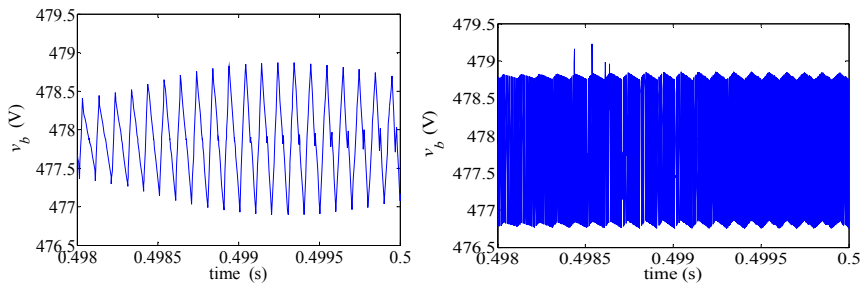

(c) dc bus voltage

Fig. 8. Simulation results for the large capacitor only case (left figs) and APF case (right figs).

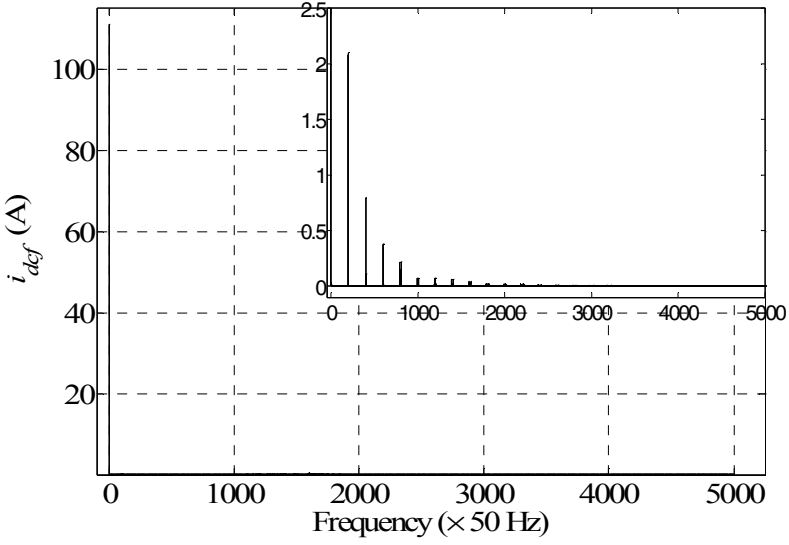

(a) Capacitor case

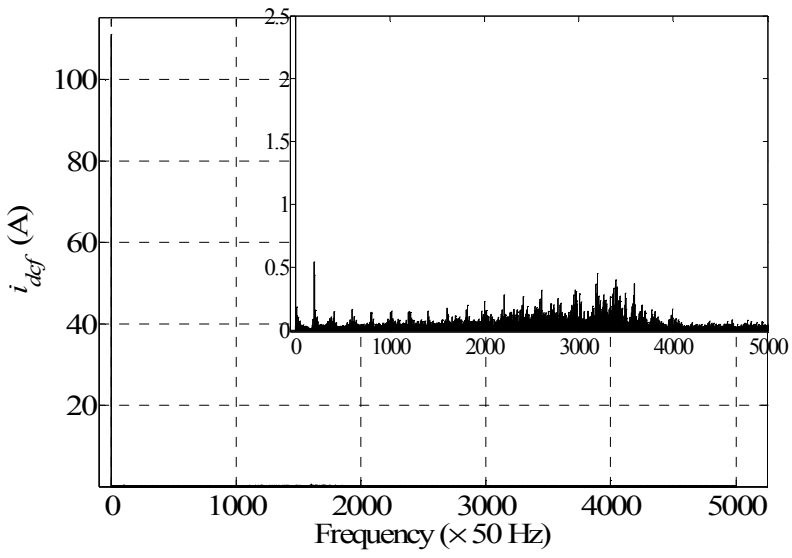

(b) APF case

Fig. 9. Harmonic spectrum of input current.

current through $250 \mathrm{kHz}$ for both cases. An enlarged figure is posted at the top right corner of each one. From the frequency spectrum, it can be seen that harmonic components are almost eliminated, leaving only the dc current. For the capacitor only case, there are small harmonic components at $f_{\mathrm{sw}} \pm 3 \times f_{\mathrm{m}}, 2 \times f_{\mathrm{sw}}$, $2 \times f_{\mathrm{sw}} \pm 3 \times f_{\mathrm{m}}, 3 \times f_{\mathrm{sw}} \pm 3 \times f_{\mathrm{m}}$ and so on. The highest magnitude harmonics are $2 \mathrm{~A}$ at $f_{\mathrm{sw}} \pm 3 \times f_{\mathrm{m}}$. For the APF case, the harmonic magnitude is much lower and spread throughout the spectrum; this is because the frequency of the ripple current is not constant in the APF method either.

\section{PARAMETER DEPENDENCE ANALYSIS AND BARRIERS}

\section{A. Analysis of Parameter Dependence}

In order to get better filtering effect and reduce the losses associated with the APF, the system performance needs to be further studied. As pointed out before, the dc bus voltage ripple, which depends on the preset controller hysteresisband, can affect the dc input current ripple. Fig. 10(a) shows the relationship between them. It is clear that, as the other circuit parameters and filter conditions remain the same, the current ripple increases as the voltage ripple monotonically 
increases. For instance, the current ripple is $10 \mathrm{~A}$ when the hysteresis-band is $2 \mathrm{~V}$, and is $25 \mathrm{~A}$ when the hysteresis-band is $5 \mathrm{~V}$. As shown in Fig. 5, it is clear that the sum of active filter current and load current charges or discharges the capacitor causing the voltage ripple in the capacitor, and the voltage change directly leads to the input current ripple. Therefore, current ripple can be controlled indirectly through the control of voltage hysteresis-band.

The switching losses in power switches are proportional to the switching frequency, suggesting that the switching frequency should be lower for reducing APF losses. According to the simulations, two crucial parameters affecting the APF frequency can be identified: dc bus voltage ripple and the smoothing capacitor. Because the active filter changes modes to charge or discharge the capacitor, increasing the voltage hysteresis-band or capacitance can increase the time of reaching the voltage boundary, which means the active filter can work at a slower frequency. The relation between frequency and voltage ripple is shown in Fig. 10(b). Since the bus ripple voltage is also proportional to the current ripple, it cannot increase too much. A tradeoff should be made to determine the voltage ripple band. A range of $2 \sim 3 \mathrm{~V}$ is acceptable in this situation. On the other hand, the capacitance of the smoothing capacitor is inversely proportional with the switching frequency. When the capacitor is 1 per-unit, i.e., $100 \mu \mathrm{F}$ in the simulation, the maximum switching frequency is $160 \mathrm{kHz}$; when the capacitor increases to 5 per-unit, the frequency can decrease to $26 \mathrm{kHz}$, as shown in Fig. 10(c). This is a more practical switching frequency for the IGBTs, and because the capacitance is one fourth of the original value, the reduction is still significant.

The parameter dependence relations can be explained by applying Coulomb's Law to the dc bus voltage:

$$
C \cdot \Delta V_{d c}=\Delta Q
$$

where $\Delta V_{d c}$ is the dc bus voltage ripple, $C$ is the capacitance, and $\Delta Q=i \cdot \Delta t$, which is the change in the capacitor charge. The change in the capacitor charge depends on $\Delta V_{d c}$ and $C$. Thus, if $C$ is kept constant, $\Delta t$, which is the charge or discharge time, is proportional to $\Delta V_{d c}$. Moreover, the average switching frequency is inversely proportional to the voltage ripple.

On the other hand, if $\Delta V_{d c}$ is kept constant, then, the switching frequency is inversely proportional with the capacitance $C$.

Furthermore, the size of the APF inductor affects the filtering of the low frequency components. With a lower inductance, all the current and voltage waveforms show increasing low frequency ripple, as shown in Fig. 11. The frequency of oscillation is three times of the inverter line frequency. This is because the inductance is too small to absorb the low frequency energy fluctuations in the dc bus.

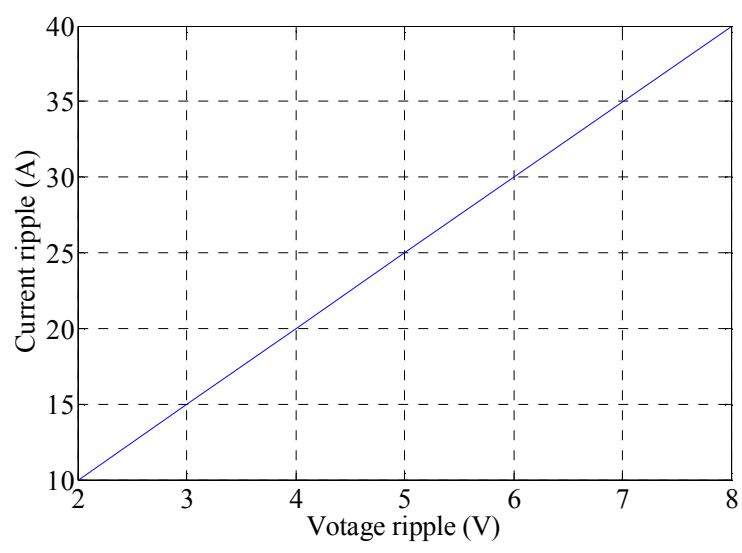

(a) p-p current ripple vs.p-p voltage ripple

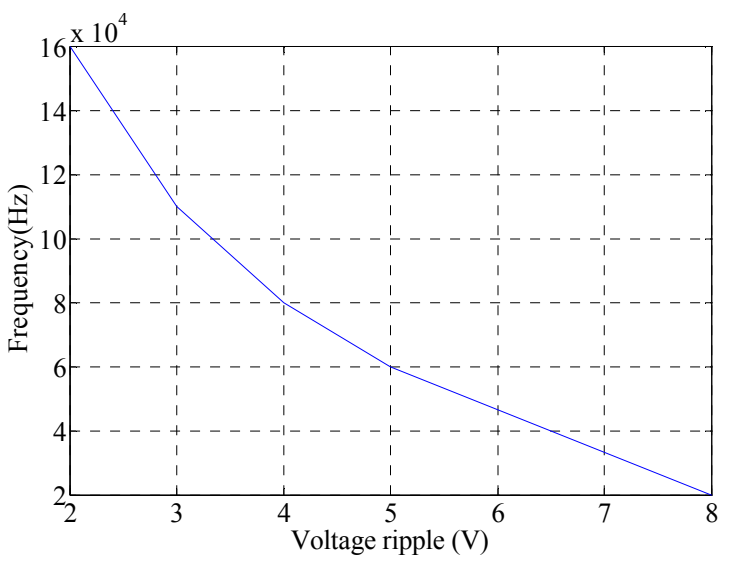

(b) switching frequency vs. p-p voltage ripple

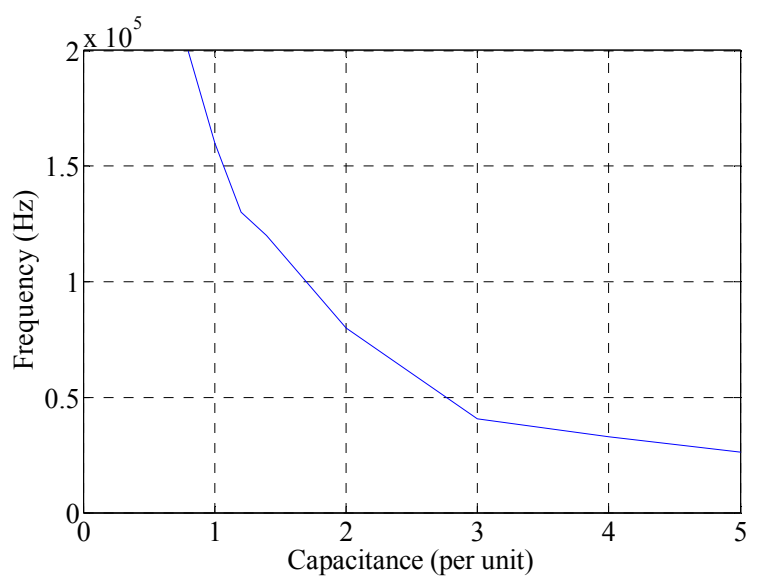

(c) switching frequency vs. capacitance

Fig. 10. Parameter dependence.

\section{B. Barriers for Practical Application}

Although the APF can replace or substantially reduce the capacitor in theory, there are several problems associated with the APF method, which limit its practical application.

Essentially, this APF solution modulates the input harmonic current to a much higher frequency; thus, only a 

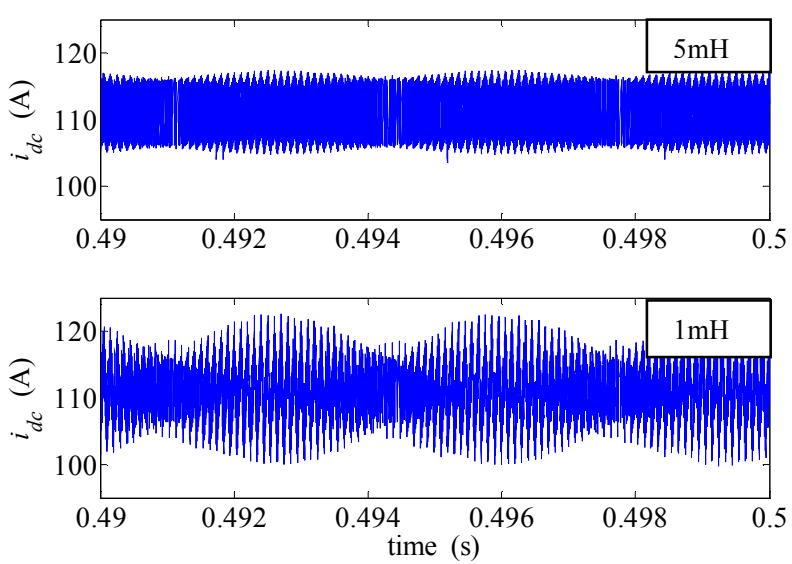

(a) Input current
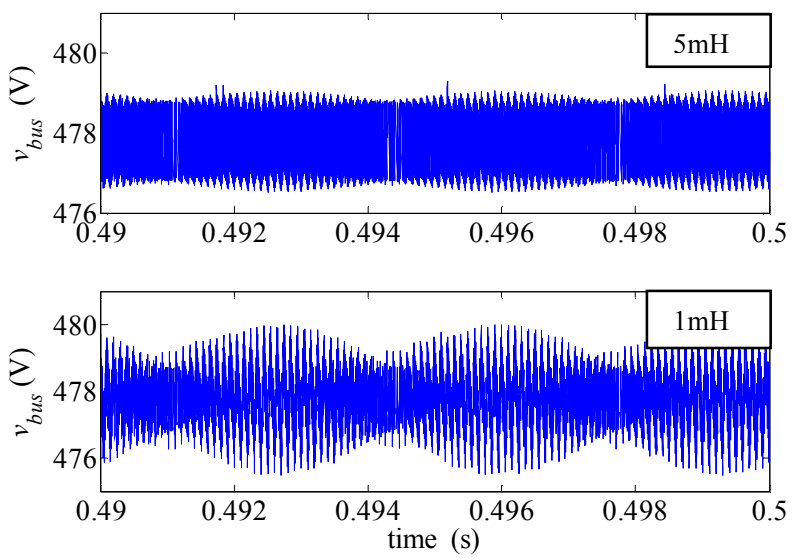

(b) dc bus voltage
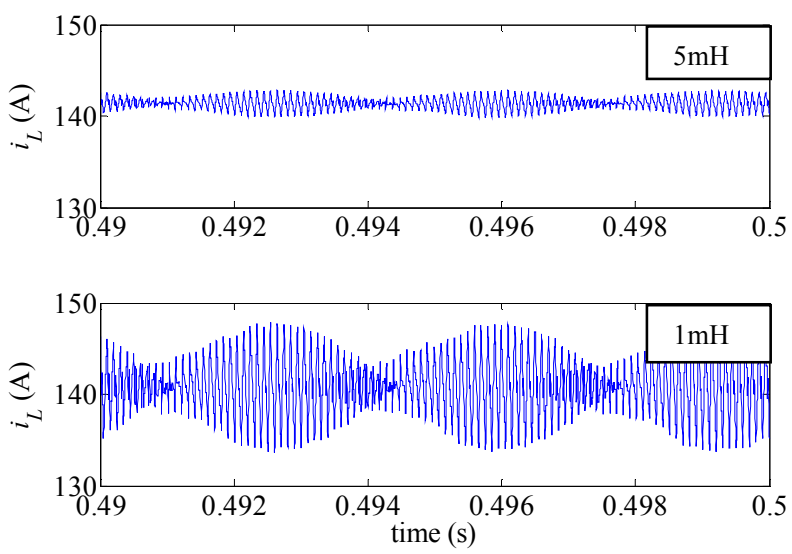

(c) APF inductor

Fig. 11. Effects of filter inductance.

small capacitor is enough for further filtering. Naturally, the disadvantages with this solution are high switching frequency. It will be hard to find power devices that can work at high frequency at these power levels. Moreover, the switching losses of the APF make up a significant portion of the losses in the inverter.
The second barrier is the high inductor current. The inductor current is around one half of the maximum load current; in this case, it is $110 \mathrm{~A}$. Thick coil wire is necessary for high inductor current. This means large volume and heavy weight of the inductor, and high ESR loss.

Although the inductor is much more reliable and long lasting than the capacitor, the power switches and diodes introduced in the APF method can decrease the reliability.

\section{CONCLUSION}

This paper evaluates a solution for reduction of the bulky dc bus capacitor by using an active power filter in a threephase traction system. Detailed operation modes are presented, and the simulation of this method is carried out by simulations. With this APF control method, the dc bus capacitor can be dramatically minimized, from $2200 \mu \mathrm{F}$ to $100 \mu \mathrm{F}$. However, because of the high operation frequency and the large inductor current, the size and weight of the APF, and the loss associated with the additional semiconductor switches, the APF method is still far from being practical in a traction drive inverter.

\section{REFERENCES}

[1] A. V. Jouanne, A. Wallace, M. MillsPrice, T. Lewis, K. Rhinefrank and E. Amon, "Hybrid electric vehicle DC-bus traction drive harmonics", in Proc. 2005 IEEE International Conf. on Electric Machines and Drives, pp: $235-242$.

[2] A. V. Jouanne, A. Wallace, M. MillsPrice, T. Lewis, K. Rhinefrank and E. Amon, "Harmonic mitigation techniques for hybrid electric vehicle DC-bus traction drives", in Proc. 2005 IEEE Conference on Vehicle Power and Propulsion, pp. 688-693.

[3] B. G. Gu and K. Nam, "A DC link capacitor minimization method through direct capacitor current control," in Proc. 2002 IEEE Industry Applications Society Annual Meeting, pp. $811-817$

[4] B. K. Bose and D. Kastha, "Electrolytic capacitor elimination in power electronic system by high frequency active filter," in Proc. 1991 IEEE Industry Applications Society Annual Meeting, pp. 869-878.

[5] W. Ping, S. Liangyu and L. Bin, "Research of inverter with the ability to harmonic compensation," in Proc. 2002 International Conf. on Power System Technology, pp. 2261 - 2264.

[6] J. S. Lai, H. Kouns, and J. Bond, "A low-inductance DC bus capacitor for high power traction motor drive inverters", in proc. 2002 IEEE Industry Applications Society Annual Meeting, pp. 955 962.

[7] B. Singh, K. Al-Haddad and A. Chandra, "A review of active filters for power quality improvement," IEEE Transactions on Industrial Electronics, vol. 46, pp. 960-972, Oct. 1999.

[8] F. Z. Peng, "Harmonic sources and filtering approaches," IEEE Industry Applications Magazine, vol. 7, pp. 18-25, July-August 2001.

[9] L. Malesani, L. Rossetto, and P. Tenti, "Active power filter with hybrid energy storage," IEEE Transactions on Power Electronics, vol. 6, pp. 392-397, July 1991.

[10] T. Shimizu, Y. Jin, and G. Kimura, "DC ripple current reduction on a single-phase PWM voltage-source rectifier," IEEE Transactions on Industry Applications, vol.36, pp.1419-1428, Sep. 2000.

[11] R. Wang, F. Wang, R. Lai, P. Ning, R. Burgos, D. Boroyevich, "Study of energy storage capacitor reduction for single phase PWM rectifier," 2009 IEEE Applied Power Electronics Conference and Exposition, pp. $1177-1183$. 